\title{
Strain-dependent constitutive analysis of three wrought Mg-Al-Zn alloys
}

\author{
F. A. Slooff $\cdot$ J. Zhou $\cdot$ J. Duszczyk $\cdot$ \\ L. Katgerman
}

Received: 14 December 2007/Accepted: 19 September 2008/Published online: 23 October 2008

(C) The Author(s) 2008. This article is published with open access at Springerlink.com

\begin{abstract}
The commonly used hyperbolic sine constitutive equation for metal forming at elevated temperatures, with no strain incorporated, is in principle applicable only to deformation in the steady state. However, the actual deformation processes applied to magnesium alloys are mostly in the non-steady state. In the present research, the results of hot uniaxial compression tests of three wrought magnesium alloys covering wide ranges of temperatures and strain rates were used for a strain-dependent constitutive analysis. A strain-dependent constitutive relationship for these alloys was established. It appeared that the apparent activation energy for deformation decreased with increasing the alloying content in these alloys. The constitutive parameters obtained were used to predict flow stresses at given strains and the results were in good agreement with experimental measurements.
\end{abstract}

\section{Introduction}

Magnesium is a lightweight metal, having a density about $35 \%$ lower than aluminium and $78 \%$ lower than steel. The specific strength of magnesium is superior to that of aluminium and steel, thus making it very attractive for weightcritical applications. When extensively used in automobiles, magnesium will contribute significantly to weight saving and in turn to the reductions of exhaust gas emissions and

F. A. Slooff $(\bowtie) \cdot J$. Zhou $\cdot$ J. Duszczyk $\cdot$ L. Katgerman Department of Materials Science and Engineering, Delft University of Technology, Mekelweg 2, 2628 CD Delft, The Netherlands

e-mail: f.a.slooff@tudelft.nl fuel consumption. Therefore, magnesium is considered a metal of great potential.

It is well known that magnesium has peculiar deformation behaviour in comparison with aluminium and steel, because of its hexagonal close-packed crystal structure. Full-scale industrial experiments to understand its deformation behaviour are far less cost-effective than computer modelling. For the latter, to obtain verifiable modelling results, reliable material parameters are of crucial importance. In order to describe the thermal viscoplastic behaviour of a metallic material during hot deformation, the following constitutive relationship is customarily used, which takes the hyperbolic sine form [1]:

$Z=A[\sinh \alpha \sigma]^{n}=\dot{\varepsilon} \exp \left(\frac{Q}{R T}\right)$,

where $Z$ is the Zener-Hollomon parameter, $A$ and $n$ are material parameters, $\alpha$ the stress multiplier, $\dot{\varepsilon}$ the strain rate, $Q$ the apparent activation energy, $R$ the universal gas constant and $T$ the absolute temperature. To obtain the activation energy for deformation and the constitutive constants in this constitutive relationship, flow stresses as a function of strain rate and temperature may be obtained from hot-working tests such as hot compression, torsion or tensile tests. In industrial forming processes, strain and strain rate may vary over several orders of magnitude and strain rate may be as high as $100 \mathrm{~s}^{-1}$. The hot-working tests to predict the material behaviour during the industrial forming processes must be performed under similar conditions. Hot torsion allows large strains [1], but the strain varies along the specimen radius, hindering the straindependent analysis. Hot tension is unfavourable, because deformation becomes inhomogeneous when necking occurs, and the strain achievable is often insufficient to cover the range of strains in industrial forming processes. 
Hot compression is capable of yielding uniform deformation even at high-strain rates as those encountered in industrial practice, provided that friction is minimised and true strain does not exceed 1.5.

Irrespective of the testing method used, Eq. 1 relates the steady-state flow stress with temperature and strain rate through the Zener-Hollomon parameter $Z$ [1, 2], without taking strain into account. Although Eq. 1 has been proven to be applicable in the modelling of metal forming processes such as hot rolling, forging and extrusion, it is in principle applicable when these processes are in the steady state. However, the deformation of magnesium and its alloys often occurs in the non-steady state. Moreover, for most of the forming processes, strain is a controlling parameter. It is therefore of great interest to explore the possibilities of deriving a strain-dependent constitutive relationship capable of correlating both the non-steadystate and steady-state flow stresses to deformation conditions in terms of strain rate and temperature.

The objectives of the present research were to ascertain the necessity of incorporating strain into the constitutive equation for different magnesium alloys under different deformation conditions and to develop a strain-dependent constitutive relationship from hot-compression tests over wide ranges of strain rates and temperatures. The constitutive behaviour of these alloys was analysed. The constitutive parameters obtained were validated by comparing the predicted flow stresses at selected strains with experimentally measured ones.

\section{Experimental details}

The three wrought magnesium alloys subjected to hotcompression tests were Mg-Al4-Zn1 (AZ41), Mg-Al6$\mathrm{Zn1}$ (AZ61) and Mg-Al8-Zn0.5 (AZ80) with their compositions given in Table 1 . The as-cast alloys were extruded at a reduction of 10:1 to the dimensions suitable for making hot-compression specimens and brought to the same as-extruded metallurgical state. The cylindrical specimens had a height of $12 \mathrm{~mm}$ and a diameter of $10 \mathrm{~mm}$. The testing temperature was varied between 250 and $500{ }^{\circ} \mathrm{C}$ and the strain rate between 0.01 and $100 \mathrm{~s}^{-1}$. Compression tests were carried out till a strain of 1 .

Table 1 Compositions of the alloys (wt.\%) investigated

\begin{tabular}{lllllll}
\hline & $\mathrm{Al}$ & $\mathrm{Zn}$ & $\mathrm{Mn}$ & $\mathrm{Si}$ & $\mathrm{Fe}$ & $\mathrm{Mg}$ \\
\hline $\mathrm{Mg}-\mathrm{Al} 4-Z n 1$ (AZ41) & 4.76 & 0.85 & 0.32 & 0.01 & 0.008 & $\mathrm{Bal}$ \\
$\mathrm{Mg}-\mathrm{Al6}-\mathrm{Zn1}$ (AZ61) & 5.6 & 0.81 & 0.18 & 0.08 & & $\mathrm{Bal}$ \\
$\mathrm{Mg}-\mathrm{A} 18-Z n 0.5$ (AZ80) & 7.81 & 0.44 & 0.23 & 0.03 & 0.009 & $\mathrm{Bal}$. \\
\hline
\end{tabular}

For hot uniaxial compression tests, a Gleeble 3800 thermo-mechanical simulator was used. The specimen chamber was flushed with nitrogen prior to heating and kept in mild vacuum to reduce the oxidation of specimen during the test. A thermocouple was welded on the surface of the specimen at the mid height for temperature control. A graphite sheet and nickel-containing paste were applied between the specimen and anvils to minimise friction during the test. The specimen was resistance-heated and soaked at the preset temperature for 75-90 s to allow the temperature to equalise. After deformation, the specimen was quenched by forced air to room temperature. As the thermocouple was unable to measure the instantaneous temperatures of the specimen correctly at high-strain rates, the thermal control was switched off during high-speed deformation tests $\left(>1 \mathrm{~s}^{-1}\right)$ and the actual specimen temperatures during the tests were calculated [3]. During highspeed deformation, the specimen temperature increased due to adiabatic deformation heating. The flow stress data obtained from the tests were corrected for temperature deviations, which are described elsewhere [4]. Isothermal stress-strain data were used in the constitutive analysis of the alloys.

\section{Results and discussion}

For the alloy AZ41, the maximum test temperature at all the strain rates was $500{ }^{\circ} \mathrm{C}$, while for AZ61 and AZ80 the applicable temperatures were restricted due to hot cracking. The reduction in the maximum temperature applicable was caused by the presence of the $\beta$-phase $\left(\mathrm{Mg}_{17} \mathrm{Al}_{12}\right)$ with a low melting temperature of $437^{\circ} \mathrm{C}$. The amount of the $\beta$-phase increased with increasing aluminium content in the alloy. In the present research, the maximum permissible temperature was defined as the highest preset temperature, where no hot shortness occurred at a strain rate of $100 \mathrm{~s}^{-1}$ to the specimen that actually had higher temperatures during the test because of deformational heating. It was found that the maximum temperature where AZ80 could be deformed at $100 \mathrm{~s}^{-1}$ without hot shortness was $375^{\circ} \mathrm{C}$. A temperature of $250{ }^{\circ} \mathrm{C}$ was too low for AZ80 because the specimen cracked due to a lack of hot ductility. The minimum test temperature at all the strain rates was thus $300{ }^{\circ} \mathrm{C}$. As AZ61 had a lower aluminium content than AZ80, no problem of hot shortness was encountered at temperatures above $437{ }^{\circ} \mathrm{C}$. The maximum temperature at which high-strain rate tests could be performed was $450{ }^{\circ} \mathrm{C}$.

Figure 1 shows typical flow stress-strain curves of AZ61 at $350{ }^{\circ} \mathrm{C}$ and different strain rates. The alloys containing 4 and $8 \mathrm{wt} \%$ aluminium displayed similar behaviour. Note that the flow stresses used to make the plot 


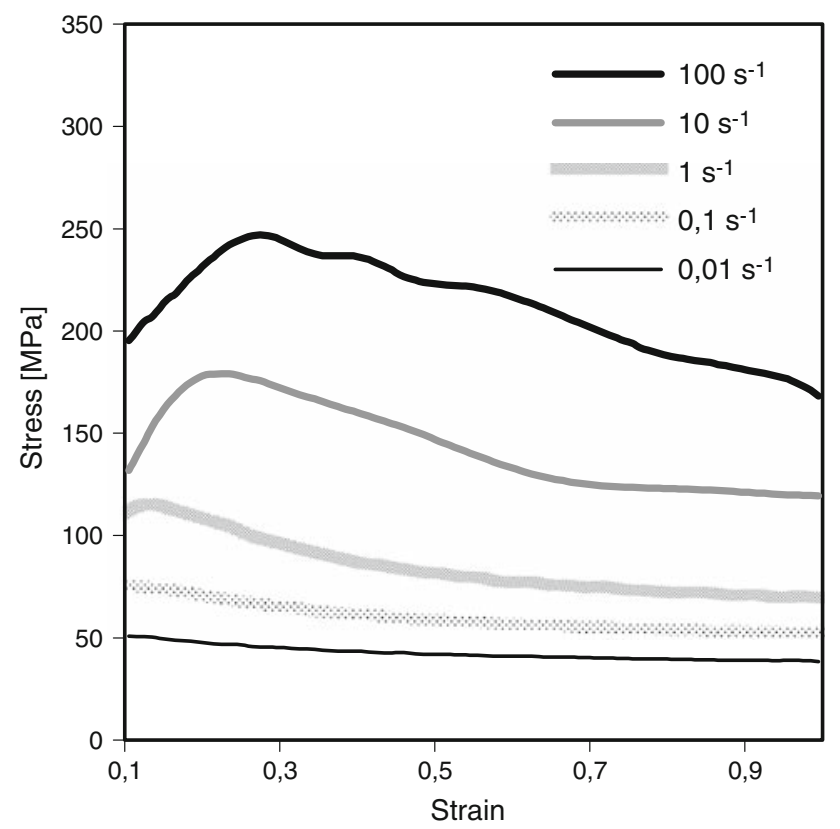

Fig. 1 Corrected flow stress-strain curves of AZ61 at $350{ }^{\circ} \mathrm{C}$ and different strain rates

were those corrected for both adiabatic heating and load cell ringing [5]. As can be seen in Fig. 1, only at low-strain rates $\left(0.01\right.$ and $\left.0.1 \mathrm{~s}^{-1}\right)$ deformation reaches a steady state after slight softening beyond the stress peak. At a higher strain rate, an increasingly large part of the stress-strain curve is in the non-steady state and therefore a straindependent constitutive relationship is of use for a large part of the deformation conditions. At the highest strain rate of $100 \mathrm{~s}^{-1}$, the steady state is not attained even till a strain of 1. The other two alloys showed the same behaviour and the strain to the peak stress is independent of the aluminium content.

Figure 2 shows the flow stress-strain curves of AZ61 at $10 \mathrm{~s}^{-1}$ and different temperatures. It can be seen that as temperature decreases, it takes a larger strain for deformation to reach the steady state. The non-steady-state deformation occurs over a wide range of strains around the stress peak, especially when deformation temperature is low. It is obvious from Figs. 1 and 2 that the peak stress decreases with increasing temperature and reducing strain rate. Of more interest is the variation of the peak height, i.e. the difference between the peak stress and the steady-state stress, with temperature and strain rate. Figure 3 shows the peak heights of the three alloys at a strain rate of $10 \mathrm{~s}^{-1}$ as a function of temperature. It is clear that the alloy with higher aluminium content has a stronger softening effect before the steady state is reached, as evident from the $\Delta$ stress values of the three alloys. Thus, the alloy composition has an influence on the peak height. In other words, for a higher aluminium-containing magnesium alloy, a strain-dependent

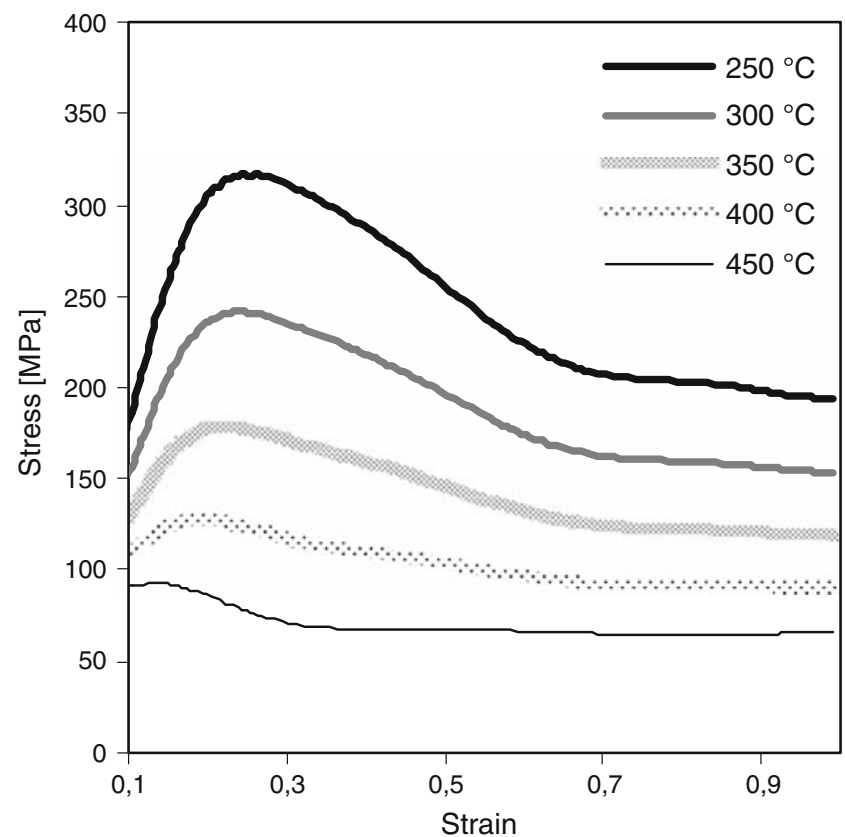

Fig. 2 Corrected flow stress-strain curves of AZ61 at $10 \mathrm{~s}^{-1}$ and different temperatures

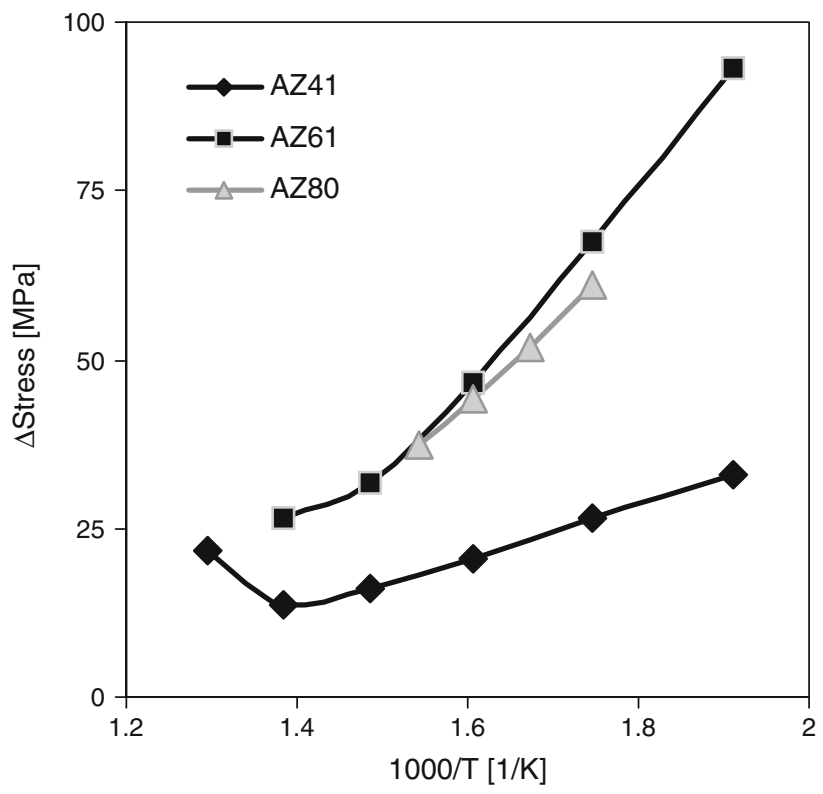

Fig. 3 Difference between the peak stress and steady-state stress as a function of the reciprocal absolute temperature at a strain rate of $10 \mathrm{~s}^{-1}$

constitutive relationship will be of more significance. At a temperature of $500{ }^{\circ} \mathrm{C}, \mathrm{AZ} 41$ shows an increase in the peak height and softening occurs at a relatively low strain. Apparently, the high-temperature facilitates the softening process because only at $500{ }^{\circ} \mathrm{C}$ the flow stress reaches the steady state within a strain of 0.4 . For these three alloys, as temperature decreases, the peak height increases, meaning 
that at a lower temperature the flow stress in the non-steady state becomes more relevant to the strain-dependent constitutive analysis.

In order to extend the applicability of the hyperbolic sine constitutive equation to the non-steady state, the material parameter $A$ in Eq. 1 may be taken as a straindependent parameter, i.e. $A_{\varepsilon}=f(\varepsilon)$. Then, the sine hyperbolic equation becomes

$Z=A_{\varepsilon}[\sinh \alpha \sigma]^{n}=\dot{\varepsilon} \exp \left(\frac{Q}{R T}\right)$.

By plotting $\ln [\sinh (\alpha \sigma)]$ against $\ln \dot{\varepsilon}$ at different temperatures [1] at fixed values of strain and adjusting the stress parameter $\alpha$, it is possible to make the plots at all the temperatures parallel within a maximum deviation of $2.5 \%$. The inverse slope of the plots is the temperaturecompensated strain rate sensitivity $n$ and is valid for every temperature investigated. An example of such a plot is shown in Fig. 4, in which the $\ln [\sinh (\alpha \sigma)]$ data of AZ41 at a strain of 0.6 are plotted. The data of the other alloys at various strains are processed in the same way. Plotting $\ln [\sinh (\alpha \sigma)]$ against $1000 / T$ [1] at fixed values of strain and strain rate, as shown in Fig. 5, gives an average slope $S$, which can then be used for calculating the apparent activation energy for deformation, i.e. $Q=R n S$. With the activation energy obtained, the Zener-Hollomon parameter $Z$ can be calculated using all the data available for different strains, strain rates and temperatures and the plot of $\ln Z$ against $\ln [\sinh (\alpha \sigma)]$ yields the values of $\ln A_{\varepsilon}$, which is the

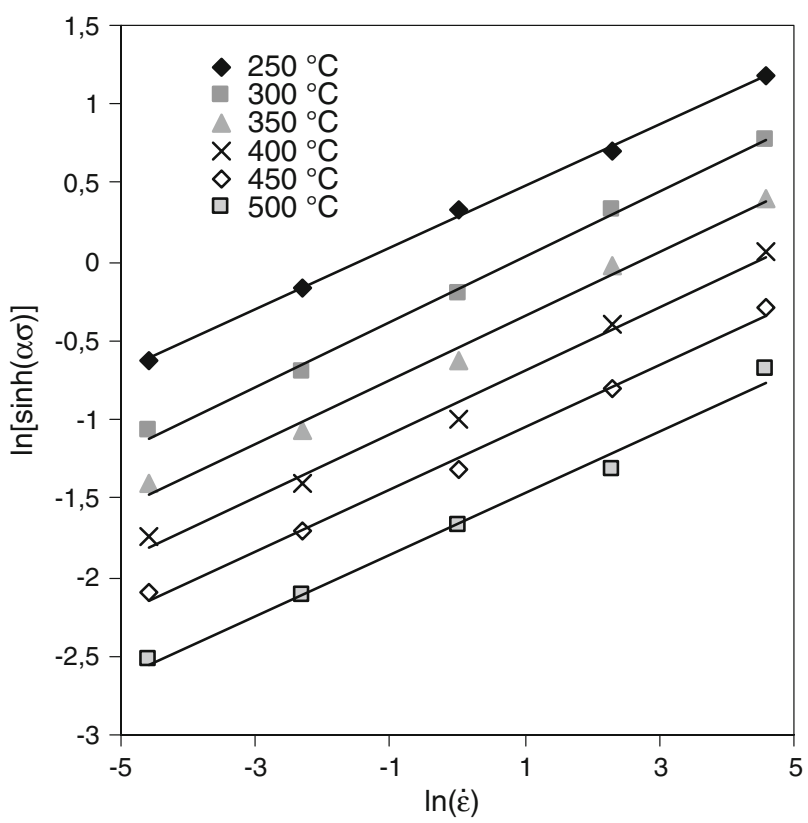

Fig. $4 \operatorname{Ln}[\sinh (\alpha \sigma)]$ against $\ln \dot{\varepsilon}$ plot for AZ41 deformed at a strain of 0.6 and different temperatures after the optimisation of the stress multiplier $\alpha$ to make the lines as parallel as possible

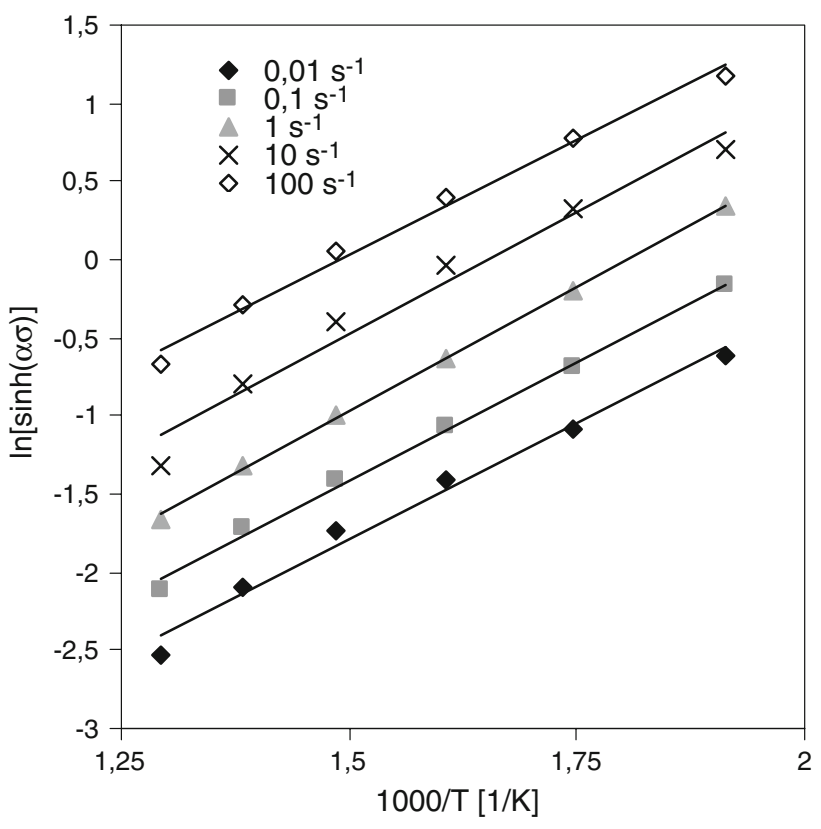

Fig. $5 \operatorname{Ln}[\sinh (\alpha \sigma)]$ against $1000 / T$ plot for AZ41 deformed at all strain rates and at a strain of 0.6 to determine the average slope $S$, for calculating the activation energy

intercept with the vertical axis. Such a plot for AZ41 at a strain of 0.6 and all the temperatures and strain rates is presented in Fig. 6.

The values of $\ln A_{\varepsilon}$ as a function of strain are shown in Fig. 7. There appears a clear distinction between these alloys; lower aluminium content in the magnesium alloy

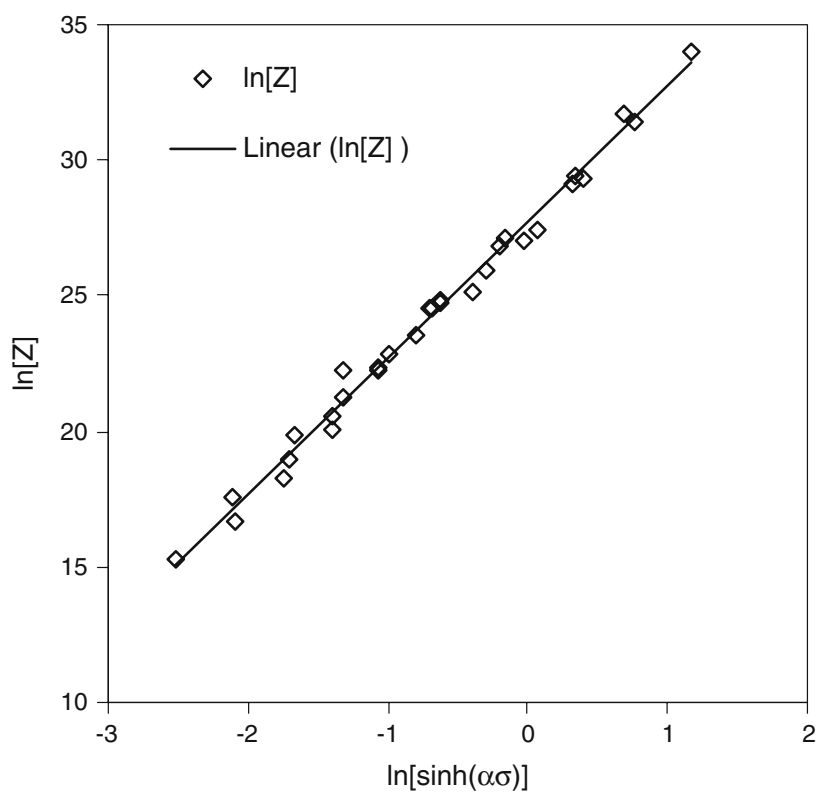

Fig. $6 \mathrm{Ln}[Z]$ against $\ln [\sinh (\alpha \sigma)]$ plot for $\mathrm{AZ41}$ deformed at a strain of 0.6 and all temperatures and strain rates to determine $\ln \left[A_{\varepsilon}\right]$, which is the intercept of the slope with the vertical axis 


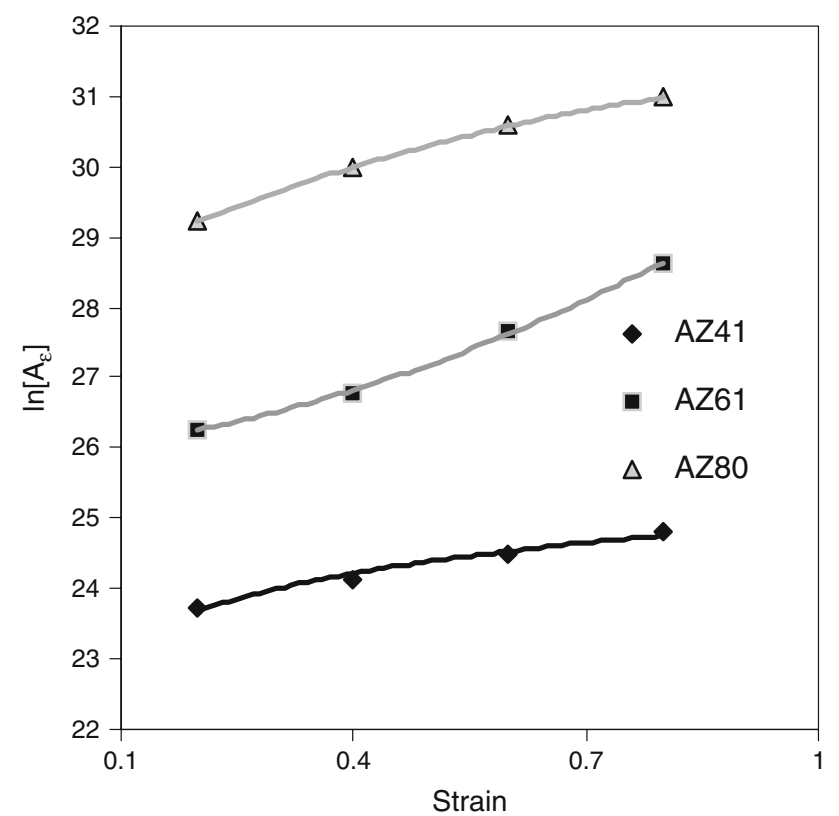

Fig. 7 Variation of $\ln \left[A_{\varepsilon}\right]$ with strain

corresponds to a lower value of $\ln A_{\varepsilon}$. Also, plotting the steady-state stress against the temperature-compensated strain rate $Z$ shows a spatial arrangement between these alloys, as shown in Fig. 8. This spatial arrangement is caused by the difference in the apparent activation energy, as given in Table 2 .

The strain-dependent constitutive analysis of the three wrought magnesium alloys investigated led to the

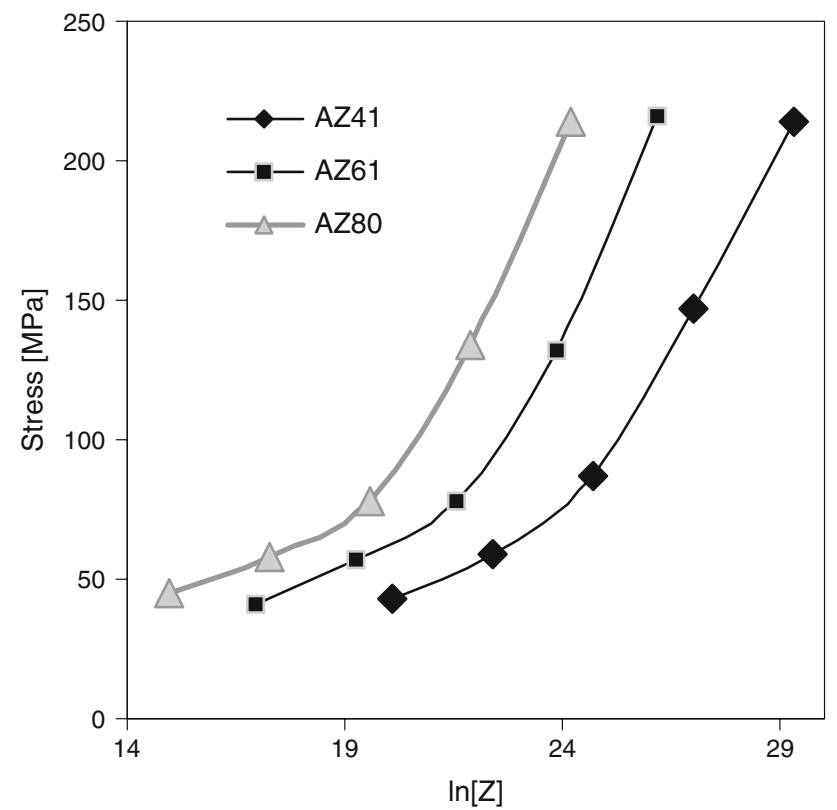

Fig. 8 Steady-state stress as a function of $\ln [Z]$ at $350{ }^{\circ} \mathrm{C}$ and a strain of 0.6
Table 2 Constitutive parameters of the $\mathrm{Mg}-\mathrm{Al}-\mathrm{Zn}$ alloys

\begin{tabular}{llll}
\hline & $Q\left(\mathrm{~kJ} \mathrm{~mol}^{-1}\right)$ & $\alpha\left(\mathrm{MPa}^{-1}\right)$ & $n$ \\
\hline AZ41 & 130 & 0.01 & 4.1 \\
AZ61 & 115 & 0.004 & 5.3 \\
AZ80 & 105 & 0.004 & 5.3 \\
\hline
\end{tabular}

constitutive parameters as given in Table 2. The stress multiplier and the stress exponent of both AZ61 and AZ80 are the same and this is considered a pure coincidence. In Table 2, it can be seen that the apparent activation energy for deformation decreases with increasing alloying content. According to the literatures [6-8], the activation energy for the self-diffusion of magnesium is approximately $135 \mathrm{~kJ} \mathrm{~mol}^{-1}$, but for magnesium alloys the activation energies may be as low as $92 \mathrm{~kJ} \mathrm{~mol}^{-1}$ [9]. It is remarkable that the activation energy decreases with increasing aluminium content. Such a correlation has not been reported previously. The constitutive parameters obtained from the constitutive analysis were used to recalculate the flow stresses at various temperatures, strain rates and strains. The typical results are presented in Fig. 9, showing the calculated flow stresses of AZ80 compared to the measured ones for all the test temperatures at a strain rate of $10 \mathrm{~s}^{-1}$. A good agreement has been reached over the complete range of test conditions. Similar results have been obtained for the other alloys and test conditions, suggesting the validity of the strain-dependent constitutive analysis performed in this research.

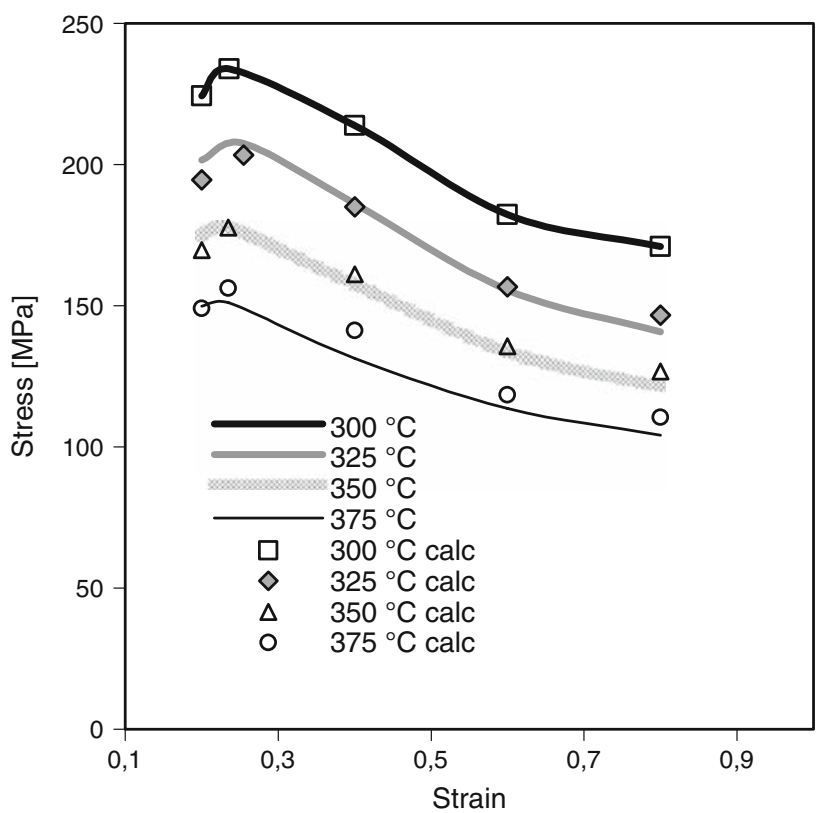

Fig. 9 Measured and calculated flow stresses of AZ80 at various temperatures and a strain rate of $10 \mathrm{~s}^{-1}$ 


\section{Conclusions}

The flow stresses of the wrought magnesium alloys, AZ41, AZ61 and AZ80, vary not only with strain rate and temperature but also with strain. The stress peak occurs at a large strain when temperature is low and strain rate high. This necessitates the incorporation of strain in the constitutive analysis. In general, the difference between the peak stress and the steady-state stress is larger when strain rate is higher and temperature lower. The alloys having higher $\mathrm{Al}$ content appear to have more softening. When the material constant $A$ in the hyperbolic sine equation is made to be strain-dependent while the other parameters are kept unchanged, the constitutive equation obtained can be used to cover the deformation both in the steady state and in the non-steady state. The apparent activation energy appears to decrease with alloying content in the Mg-Al-based alloys.

Acknowledgement The authors gratefully acknowledge the Innovative Research Programme (IOP) for funding this research under project code IOT 3003.
Open Access This article is distributed under the terms of the Creative Commons Attribution Noncommercial License which permits any noncommercial use, distribution, and reproduction in any medium, provided the original author(s) and source are credited.

\section{References}

1. McQueen HJ, Ryan ND (2002) Mater Sci Eng A32:43

2. Sheppard T (1999) Extrusion of aluminium alloys. Kluwer, Dordrecht

3. Goetz RL, Semiatin SL (2001) J Mater Eng Perform 10:710

4. Slooff FA, Zhou J, Duszczyk J, Katgerman L (2007) Scr Mater 57:759

5. Slooff FA, Zhou J, Duszczyk J, Katgerman L (2006) In: Kainer KU (ed) Magnesium. Wiley, Weinheim

6. Guo Q, Yan HG, Zhang H et al (2005) Mater Sci Technol 21:1349

7. Mwembela A, Konopleva EB, McQueen HJ (1997) Scr Mater 37:1789

8. Li L, Zhou J, Duszczyk J (2006) J Mater Process Technol 172:372

9. Galiyev A, Kaibyshev R, Gottstein G (2001) Acta Mater 49:1199 